\title{
TENDÊNCIA DA PESQUISA EM ENFERMAGEM
}

\section{Maguida Costa Stefanelli*}

Falar sobre tendências da enfermagem na virada do século é um desafio, em face das mudanças socio-político-culturais, economicas, ecológicas, surgimento e aumento de minorias carentes mesmo nos países mais desenvolvidos, mudanças nas políticas de saúde e de educação em todos os níveis. Estas alterações se dão de maneira tão acelerada que é difícil acompanhá-las.

Abordaremos, portanto, as tendências atuais da pesquisa, ou seja, o estado atual e direção para um futuro próximo.

Ao entrarmos num novo século creio que precisamos conhecer muito bem nosso passado, viver e construir o momento presente encontrando modos para transformar a ansiedade gerada pelas mudanças em energia para uma ação construtiva, cada vez mais sustentada, apoiada por resultados de pesquisa.

A preocupação com a pesquisa em enfermagem vem se dando de modo crescente; isto pode ser constatado pelo número de centros de pesquisa e pelos dados citados na conferência que precedeu esta mesa redonda.

A realização de eventos, nacionais e internacionais, de diversas naturezas para debate sobre pesquisa é também, de suma importância para o desenvolvimento e disseminação do conhecimento em enfermagem em suas grandes áreas - assistencial ou do cuidado, administrativa, educacional e de pesquisa.

O campo do conhecimento gerado e legitimado pela pesquisa é condição "sine qua non" para a existência da enfermagem como ciência, a fím de que esta possa manter-se no mesmo nível das outras profissões, ocupando com competência e qualidade seu lugar no sistema de saúde e na sociedade em geral: só assim poderá atender ao seu fim último que é melhor qualidade de vida de sua clientela e conseqüentemente da sociedade.

Esse conhecimento tem, portanto, de fazer parte formal do processo ensino-aprendizagem, nos cursos de graduação e de pós-graduação, e ser espelhado na prática assistencial.

Para tanto temos de pesquisar problemas de enfermagem e aplicar seus resultados na prática e, reforço aqui, a prática assistencial e educacional em enfermagem.

O conhecimento produzido tem de oferecer elementos que suportem a

- Enfermeira. Professora Titular e Vice-Diretora da Escola de Enfermagem da Universidade de São Paulo. 
nossa prática visando a excelência desta. No trabalho de CIANCIARULLO; SALZANO (1990), como continuidade do de NOGUEIRA (1982), vemos que os temas necessidades do paciente e "metodologia da enfermagem" ocupam o primeiro e segundo lugar nas pesquisas das enfermeiras brasileiras, ficando o ensino de enfermagem em terceiro lugar.

Resultado semelhante foi encontrado em levantamentos nos últimos 4 (quatro) anos, efetuados em três periódicos internacionais - um dos EUA, um do Canadá e um da Inglaterra, respectivamente Nursing Research, Nursing Papers (agora denominada Journal of Canadian Nursing Research) e Journal of Advanced Nursing. Este é um ponto que merece atenção dos pesquisadores.

Abordaremos a tendência da pesquisa em relação à metodologia; fatores que têm determinado o incremento de pesquisas em enfermagem, quem pesquisa e quais as áreas investigadas; disseminação do conhecimento; implementação dos resultados na prática e outras considerações gerais.

\section{METODOLOGIA}

O desenvolvimento da metodologia da pesquisa para sedimentar o corpo de conhecimento da enfermagem é um desafio que está sendo enfrentado pelas enfermeiras.

Não é tarefa fácil encontrar o método ideal para estudar processo e padrões de comportamento do homem em relação à saúde, como um ser que interage com seu ambiente físico e sócio cultural, como estáo tentando fazer as enfermeiras. Evidenciamos aqui que o método é um instrumento - meio para encontrarmos soluçōes para nossas próprias questōes.

É tendência, entre as enfermeiras, o uso de uma pluralidade de métodos. Elas estão utilizando perspectivas teóricas e metodológicas de outras disciplinas como Antropologia, Sociologia, Psicologia e Fisiologia na busca de melhor compreensão dos fenomenos vivenciados na enfermagem.

Esta diversidade de métodos é benéfica pois permite o estudo de um mesmo fenómeno sob a ótica de vários enfoques, assim como a apreensão e compreensão do fenómeno, no seu todo, de modo naturalístico. O importante é mantermos a coerência entre eles quando usada a triangulaçáo.

Acreditamos que tanto métodos quantitativos como qualitativos têm seu espaço assegurado na enfermagem.

Temos de optar pelo método que melhor responda à questão em estudo. É a questão, o problema que nos vai permitir verificar qual o método a ser adotado - qualitativo ou quantitativo. Cabe ressaltar que não podemos colocar o, método acima do nosso intelecto, raciocínio e discernimento.

O rigor científico, de modo geral, está sendo observado e tem sido explicitado nos trabalhos publicados em periodicos, dissertaçôes e teses.

A validação do instrumento precisa ser incentivada e também registrada nas pesquisas. Em nivel internacional, a maioria dos periódicos tem considerado este fator em suas publicaçōes. No Brasil já está havendo, igualmente, esta preocupação.

A triangulação em pesquisas vem sendo utilizada com resultados considerados satisfatórios por uns e criticados por outros autores, tanto nacionais como internacionais. 
Cremos ser necessário o uso de diferentes métodos e instrumentos. A coerência entre eles, entretanto, deve ser mantida e seus pressupostos básicos respeitados.

Encerramos aqui os comentários sobre metodologia porque este é tema de uma das conferências deste Encontro.

\section{FATORES QUE INFLUENCIAM O INCREMENTO DA PESQUISA}

Os fatores preponderantes no desenvolvimento da pesquisa são, basicamente, a necessidade de mantermos a profissão entre as de nível universitário e a instalação de programas de pós-graduação, em nível de Mestrado e Doutorado (CIANCIARULLO; SALZANO, 1990), além da política das agências financiadoras de pesquisa.

\section{Pós-Graduaçáo}

Na América do Norte, em especial nos EUA, a existência de programas de pós-graduação é uma realidade, embora no Canadá exista menor número de programas de Doutorado (TASK FORCE ON INTERNATIONAL NURSING RESEARCH, 1990).

No Brasil temos 12 cursos de mestrado, com aproximadamente 750 Mestres titulados, e 6 de Doutorado, com 70 doutores titulados.

Há uma tendência de expansão dos Programas de Pós-Graduação, a exemplo do da Escola de Enfermagem da Universidade de São Paulo em Belo Horizonte, Minas Gerais, para capacitar pesquisadores em enfermagem..

A influência destes programas na produção cientifica fica bem evidente no trabalho de CIANCIARULLO; SALZANO (1990).

Podemos constatar neste que $98,2 \%$ das pesquisas realizadas por enfermeiras brasileiras foram desenvolvidas nos últimos 20 anos, período que corresponde à existência da Pós-graduação em Enfermagem no Brasil.

Se considerarmos que a maioria dos alunos de pós-graduaçáo são docentes, podemos afirmar que os docentes lideram a produção das pesquisas, em geral Mestres ou Doutores, e seus orientandos - mestrandos e doutorandos, o que está de acordo com os achados de VIEIRA (1980).

Esta conclusão aplica-se também ao nível internacional, afirmação feita com base no levantamento efetuado nos periódicos já citados neste levantamento, na análise dos quais verificamos que quem mais publica são também docentes, portadores de título de Mestre, Doutor, inclusive Ph.D. (Doutor em Filosofia), ou alunos dos programas de mestrado, doutorado e pós-doutorado.

Encontramos trabalhos realizados por enfermeiras assistenciais, e outros com participação de estatísticos, antropólogos, sociólogos e psicólogos entre outros profissionais.

Analisando as inscrições nos Programas de Pós-Graduação no Brasil, verificamos que a sua procura por enfermeiras da área assistencial está aumentando gradativamente. Isto pode significar mudanças na política das instituições de saúde, privadas e governamentais. Poderíamos inferir que estas enfermeiras estariam na vanguarda por melhor qualidade do cuidado de enfermagem e da qualidade de vida de sua clientela. Acontece, no entanto, que estas ao receberem os 
títulos de Mestre ou Doutor são, em sua grande maioria, absorvidas pelas escolas de enfermagem ou ocupam cargos de liderança administrativa. Há algumas instituições assistencias, governamentais e privadas, que já estimulam a criação de grupos de enfermeiras pesquisadoras, com o objetivo de melhorar a qualidade da assistência de enfermagem.

Acreditamos que, como fruto da pós-graduação, a utilização dos modelos teóricos de enfermagem nas pesquisas vem sendo evidenciada. Há já vários trabalhos de validação de alguns modelos ou então o emprego destes, como referencial teórico das pesquisas realizadas. Poderíamos citar os modelos de Orem, Leininger, Peplau e King, entre outros, em nivel internacional e o de Horta, entre nós.

\section{Núcleos de Pesquisa}

Precisamos, cada vez mais de Programas de Pós-graduação em núcleos de pesquisa para que o conhecimento, das diversas áreas de enfermagem, possa ser sedimentado.

Esses núcleos têm suas linhas definidas de pesquisa, o que permite assegurar o desenvolvimento do conhecimento em profundidade, sem ampliação descontrolada do nosso campo de ação.

É fundamental que se articulem núcleos regionais, nacionais e internacionais, visando um desenvolvimento conjunto.

No Brasil já temos vários núcleos em diferentes níveis de desenvolvimento, em geral localizados nas escolas de enfermagem. Tais grupos contam com enfermeiras de várias escolas e tendem à interdisciplinaridade ou multiprofissionalidade. Este fato é constatado, também, no levantamento internacional feito para o presente estudo e no exemplar dos Anais da Task Force on International Nursing Research.

As linhas de pesquisa da Escola de Enfermagem da Universidade de São Paulo estão sendo reestruturadas pela Comissão de Pesquisa da mesma, com o suporte dos departamentos e, portanto, com a colaboração de todos os docentes. Em versão preliminar, as seguintes linhas foram definidas até o momento, pela Comissão de Pesquisa da EEUSP (1992): Ensino-aprendizagem do aluno; Ensino-aprendizagem do paciente-cliente; Ensino-aprendizagem do profissional; Aspectos nutricionais do processo saúde-doença; Desenvolvimento tecnológico na saúde; Comunicação no processo saúde-doença; Aspecto psicossocial do processo saúde-doença; Assistir-cuidar em enfermagem; Modelos teóricos e conceituais em enfermagem; Epidemiologia de causas externas; Epidemiologia social; Gerenciamento de recursos humanos; Instrumento do processo de trabalho.

\section{IMPLEMENTAÇÃO DE RESULTADOS NA PRÁTICA}

Há vários trabalhos na literatura internacional publicados em livros ou periódicos, bem como da literatura nacional publicados em periódicos nos quais o assunto é abordado especificamente ou é mencionado nas análises de outras pesquisas (HORSLEY, 1983; STEFANELLI et al, 1987; STEFANELLI; FRIEDLANDER, 1991). 
Apesar do nosso desenvolvimento em pesquisa o seu reflexo não é observado na prática. O vácuo entre a pesquisa e a utilizaçáo de seus resultados é muito preocupante.

Vários projetos já tentaram reduzir a distância entre academia e prática. Vários fatores têm impedido a sua continuidade, entre os quais poderfamos citar a rotatividade das enfermeiras, baixa remuneração, não existência de turnos fixos de trabalho, escassez de enfermeiras nas instituições e disposição para participação deste tipo de ação.

Muitas vezes há número suficiente de profissionais, porém a pesquisa não faz parte da política da instituição.

Além destes fatores, leitura, discussão e aplicação de resultados de pesquisa na prática assistencial não são características da maioria das enfermeiras (PHILLIPS, 1986; CIANCIARULLO, CASTELLANOS, STEFANELLI, 1991).

Em geral, o foco do ensino da pesquisa, nos cursos de graduação e nos livros textos, está centrado na elaboração e execução de um projeto, sem a preocupação da continuidade e do engajamento dos alunos em projetos mais amplos ou núcleos de pesquisa.

Pouco se encontra sobre a aplicabilidade ou utilidade dos resultados destes projetos na prática assistencial. Estas questões geram as dificuldades que as enfermeiras assistenciais encontram para criticar pesquisa; é essencial não só que elas saibam fazer pesquisa como, também, aprendam a consumir resultados de pesquisa (PHILLIPS, 1986).

Para que isto ocorra é necessário que haja a inserção do ensino da pesquisa nos currículos de graduação em enfermagem, considerando-a como eixo integrador que permeia todas as experiências curriculares vivenciadas pelo aluno (CIANCIARULLO; CASTELLANOS; STEFANELLI, 1991).

Ressaltamos aqui a importância do papel do orientador de pesquisa na formação do pesquisador, ao criar e articular formas de envolver alunos de graduação, pos-graduação e enfermeiras da área assistencial em torno de temas comuns e em linhas de pesquisa, tendo como objetivo a interdisciplinaridade e atuação multiprofissional.

Isto já seria, ou poderíamos dizer, já é o início do preparo para a aplicação de resultados de pesquisa na prática. Na literatura americana encontramos alguns modelos que norteiam esta aplicação (PHILLIPS, 1986). Dentre estes, destaca-se um do qual temos conhecimento mais próximo, a saber: o Curn Project Conduct and Utilization of Research in Nursing Project. Percebeu-se que pode-se influenciar positivamente a qualidade do cuidado com a implementação dos resultados de pesquisas.

É essencial o compromisso da organização e, especificamente, do Departamento de Enfermagem para que haja um impacto sobre a prática. Isto tem de ser realizado de modo a integrar enfermeiros pesquisadores, docentes e assistenciais, num modelo de articulação docente-assistencial porque a pesquisa é essencial para guiar a prática e, também, porque gera para a enfermeira conhecimento e compreensão dos fenômenos da enfermagem. Este conhecimento pode ser usado para capacitar indivíduos, famílias e comunidades para atingir melhor qualidade de saúde e de vida.

Considerando o que foi dito, o compromisso da enfermeira com a pesqui- 
sa torna-se imperioso, uma vez que somente uma minoria da população mundial tem vida saudável.

Resumindo as tendências apresentadas teríamos:

1. Inserção da pesquisa como eixo integrador do currículo.

2. Aumento da produção de pesquisas.

3. Utilização de vários métodos e marcos teóricos.

4. Implementação de programas de pós-graduação.

5. Criação de núcleos de pesquisa com foco na interdisciplinaridade.

6. Implementação dos resultados na prática.

7. Articulação docente-assistencial, em especial no que tange à atenção primária. Para que estas tendências sejam sedimentadas e dêem origem a outras, é necessário que seja incentivada a publicação das pesquisas realizadas e a disseminação de seus resultados em periodicos, livros, eventos, bem como a decodificação dos resultados das pesquisas para que seja facilitada sua implementação. A linguagem do pesquisador tem de ser adequada à linguagem da prática.

Em resumo, com base no que foi dito, temos de pesquisar, divulgar, disseminar resultados encontrados, articular docência e assistência e não medir esforços para o desenvolvimento dos nossos pares.

Temos de ter coragem, compromisso, competência e responsabilidade para oferecer à sociedade o retorno que ela espera.

\section{REFERÊNCIAS BIBLIOGRÁFICAS}

CIANCIARULlO, T.; SALZANO, S.D.T. A enfermagem e a pesquisa no Brasil. Rev.Esc.Enf.USP, v.25, n.2, p.195-213, 1991.

CIANCIARULlo, T.; STEFANELLI, M.C.; CASTELLANOS, B.E.P. O Relatório da Oficina de Trabalho "O ensino de pesquisa nos cursos de graduação e pós-graduação". /Apresentado no Seminário Nacional de Pesquisa em Enfermagem, 6. Associação Brasileira de Enfermagem, Rio de Janeiro, 1991/

HORSLEY, J.A. et al. Using research to improve nursing practice: a guide. Philadelphia, W.B. Saunders, 1983.

NOGUEIRA, M.J.C. A pesquisa em enfermagem no Brasil: retrospectiva histórica. Rev.Esc.Enf.USP, v.16, n.1, p.17-26, 1982 .

PHILLIPS, L.R.F. A clinician's guide to the critique and utilization of nursing research. Norwalk, AppletonCentury-Crofts, 1986.

STEFANELLI, M.C.; FUKUDA, I.M.K.; ROLIM, M.A.; ARANTES, E.C. Situação da pesquisa em enfermagem psiquiátrica no Brasil. Rev. Bras. Enf., v.40, n.1, p.60-5, 1987.

STEFANELLI, M.C.; FRIEDLANDER, M.R. Importância dos programas de pớs-graduação para o desenvolvimento técnico-cientifico da enfermagem. Apresentado na Reunião " Desenvolvimento da Enfermagem para a América Latina", Rio de Janeiro, 1992.

TASK FORCE ON INTERNATIONAL NURSING RESEARCH, Geneve, 1990. Nursing research worldwide: current dimensions and future directions. Geneve, National Center for Nursing Research/International Council of Nurses, 1990.

VIEIRA, T.T. Produção cientlfica em enfermagem no Brasil: 1970-1979. Salvador, 1980. Tese (Professor Titular) - Escola de Enfermagem, Universidade Federal da Bahia. 